Valparaiso University

ValpoScholar

Nursing and Health Professions Faculty

Publications

Nursing and Health Professions Faculty

2008

\title{
Girl Scout Badge Day as a Service Learning Experience
}

Nola A. Schmidt

Valparaiso University

Janet M. Brown

Valparaiso University

Follow this and additional works at: https://scholar.valpo.edu/nursing_fac_pubs

\section{Recommended Citation}

Schmidt N. A \& Brown, J. M. (2008). Girl Scout Badge Day as a service-learning experience. International Journal of Nursing Education Scholarship, 5(1), 1-14.

This Article is brought to you for free and open access by the Nursing and Health Professions Faculty at ValpoScholar. It has been accepted for inclusion in Nursing and Health Professions Faculty Publications by an authorized administrator of ValpoScholar. For more information, please contact a ValpoScholar staff member at scholar@valpo.edu. 


\title{
International Journal of Nursing Education Scholarship
}

Volume 5, Issue 1 2008

Article 36

\section{Girl Scout Badge Day as a Service Learning Experience}

\author{
Nola A. Schmidt* Janet M. Brown ${ }^{\dagger}$
}

*Valparaiso University, nola.schmidt@ valpo.edu

†Valparaiso University, janet.brown@valpo.edu

Copyright (c)2008 The Berkeley Electronic Press. All rights reserved. 


\title{
Girl Scout Badge Day as a Service Learning Experience
}

\author{
Nola A. Schmidt and Janet M. Brown
}

\begin{abstract}
Acquiring clinical experiences for students is a major challenge for nurse educators. One of the most difficult areas in which to secure clinical experiences is pediatric nursing; yet, nurse educators have a responsibility to create innovative strategies to assure that students have experience with pediatric clients. The purpose of this paper is to describe Girl Scout Badge Day (GSBD), a teaching strategy rooted in service learning. The strategy incorporates the three essential elements that distinguish service learning from other learning: experiential learning, reflection, and reciprocal learning. During this clinical experience, students provide health promotion education to scouts who subsequently earn badge requirements. Students are provided experiential learning as they implement the role of the teacher and reflect on the core values of nursing. In this paper, the specifics of implementing GSBD are presented and lessons learned are discussed. Benefits for students, scouts, troop leaders, and faculty are identified and improvements are suggested.
\end{abstract}

KEYWORDS: service learning, nursing education, pediatrics, health education 
Acquiring clinical experiences for students is a major challenge for nurse educator. One of the most difficult areas in which to secure clinical experiences is pediatric nursing. Changes in health care, such as increases in outpatient surgery and decreases in length of stay, have reduced the numbers of children admitted to hospitals. Furthermore, as enrollments in nursing programs increase, competition among schools for limited clinical sites has contributed to the challenge. Initiating pediatric clinical experiences in the community is one way to create new learning opportunities. The purpose of this paper is to describe an educational strategy that engages undergraduate nursing students in a service learning project. Girl Scout Badge Day (GSBD) is a program that (a) provides health promotion education for young girls, in the context of earning badge requirements, and (b) experiential learning for nursing students who implement the role of teacher and reflect on the vocation of service. The project can easily be adapted to international groups such as Girl Guides.

\section{LITERATURE REVIEW}

\section{Overview of Service Learning}

Service learning is a pedagogy designed to engage universities with communities in ways that enhance students' academic experiences and simultaneously serve the needs of communities (Champagne, 2006; The International Partnership for Service-Learning and Leadership, 2006; Learn and Serve America's National Service-Learning Clearinghouse, 2008). Service learning as a teaching methodology is well established internationally, with programs in Vienna, Geneva, and Ljubljana, Slovenia recognized as exemplars for service learning (Silcox \& Leek, 1997). A variety of disciplines, including nursing, medicine, physical therapy, and nutrition, have embraced this pedagogy.

Service learning originated with John Dewey in the early 1900s. Dewey proposed three essential elements that must be present to distinguish service learning from other learning experiences: (a) experiential learning, (b) reflection, and (c) reciprocal learning. According to Dewey, educational strategies that connect students to the realities of society are critical. Activities addressing social concerns, while fostering learning, are preferable to activities that promote passivity on the part of students. By using reflection, students come to understand phenomena rather than simply know them (Champagne, 2006).

Through partnerships among universities and communities, reciprocal learning involves all collaborating parties. To achieve long term success, particularly in health related venues, individual and community empowerment is 
critical (Champagne, 2006; The International Partnership for Service-Learning and Leadership, 2006; Learn and Serve America's National Service-Learning Clearinghouse, 2008).

Benefits. Service learning benefits students, faculty, academic institutions, community organizations, and community members (Seifer, 1998). It positively affects the interpersonal, spiritual, and moral development of students (Greene, 1997; Hester, Daniels, \& Adonis, 2005), who develop enhanced leadership, communication, and problem solving abilities. They can achieve a heightened sense of civic responsibility, sensitivity to cultural diversity, and a willingness to volunteer in the future (Astin, Vogelgesang, Ikeda, \& Yee, 2000; Champagne, 2006). Faculty who use service learning report increased satisfaction with the quality of student learning as well as stronger relationships among students and faculty (Champagne). Service learning raises the visibility and enhances the reputations of academic institutions in communities, while offering opportunities for collaboration on research and social policies (Champagne; Seifer). Benefits for community organizations include reaching more people and increasing the variety and quality of services provided (Champagne). Changes in health behaviors resulting in improved health outcomes have been realized by service learning projects (Reising, Allen, \& Hall, 2006a).

Barriers. A number of barriers to the use of service learning have also been identified (Champagne, 2006). A major obstacle for students and faculty is the perception that service learning is more time consuming than traditional learning experiences. In addition, faculty members report a lack of rewards and recognition for creating service learning projects. Although the philosophy of service learning is embraced by many universities, they have been slow to implement support systems needed for service learning to become a well established pedagogy.

\section{Service Learning in Nursing Education}

In the United States, there has been a resurgence of interest in the use of service learning as an educational strategy. Community-Campus Partnerships for Health, which is under the auspices of the Pew Charitable Trusts, a philanthropic organization committed to stimulating civic life, was initiated in 1997 for the purpose of fostering partnerships between universities and communities to improve health (Champagne, 2006). Furthermore, The Higher Learning Commission (2003), an organization dedicated to the accreditation of colleges and universities, has established an accreditation criterion of engagement and service. Educational institutions must identify their stakeholders and create service 
oriented programming to meet that criterion. Service learning is especially compatible with recent efforts to infuse nursing curricula with community-based experiences. The American Association of Colleges of Nurses (AACN) has endorsed the shift from traditional education models to community-based curricula (AACN, 1999). Community-based nursing education involves emphasis on the integration of teaching, service to community, practice, and research. The reflection element of service learning provides opportunities for students to develop the core values of professional nursing, which include altruism, autonomy, human dignity, integrity, and social justice (AACN, 1998).

Nursing courses focusing on health promotion and screening are ripe for students to make contributions to the health of communities through the implementation of service learning projects. For example, Hamner, Wilder and Byrd (2007) partnered with a low income public housing provider to administer nursing care in a clinic. Physical assessments, glucose and cholesterol screenings, and health teaching on topics identified by residents were offered. Similar services have also been offered for university employees (Reising et al., 2006b). Other examples include health promotion teaching to pregnant adolescents to prepare them for parenthood (Bentley \& Ellison, 2005); and door-to-door administration and reading of Mantoux tests (Bittle, Duggleby, \& Ellison, 2002).

Service learning and pediatric nursing experiences. Service learning can be an alternative to the traditional hospital-based pediatric clinical experience. Kendle and Zoeller (2007), for example, developed a service learning project with a Catholic parish. Students developed professional relationships with families who have children with special needs. They provided 16 hours (approximately $20 \%$ of the pediatric clinical experience) of respite care using the concept of family-centered care. Student activities included administering tube feedings, medications, respiratory treatments, and suctioning. They completed a nursing care plan and assignments that required reflection.

To help students meet objectives about developing physical assessment skills, implementing the role of teacher, and applying the principles of growth and development. Kulewicz (2001) partnered with Head Start, a program that provides child development courses for $2-5$ year olds. Students provided blood pressure, height, weight, vision, hearing, and lead screenings; and conducted Denver II Developmental Screening Tests and Denver Articulation Screening Exams. They also created and implemented health promotion and safety teaching projects, and interacted with children to observe cognitive, motor, speech, and social skills. At the conclusion of this 6-hour clinical experience, each student presented a clinical 
or research article about pediatric health or safety. In their evaluation, students reflected on how the children and school benefited from their presence.

Other examples of community-based pediatric clinical experiences (Kushto-Reese, Maguire, Sibert-Flagg, Immelt, \& Shaefer, 2007; Lemon. 2001; Miller \& Swanson, 2002) do not describe how reflection is incorporated. Yet, reflection is a foundational element that links service and learning to optimize the educational experience (Eyler \& Giles, 1999).

In summary, there is a proliferation of examples of service learning projects in the nursing literature, many of which involve pediatric clinical experiences as alternatives to traditional hospital-based learning opportunities. Student learning objectives are successfully achieved; community needs are met; projects are mutually beneficial; and participants' perceptions are positive. However, some authors report that service learning projects can require extensive faculty time, resources, and energy.

\section{GIRL SCOUT BADGE DAYS AS A SERVICE LEARNING CLINICAL EXPERIENCE}

GSBD is an effective way to foster the role of teacher in undergraduate students while meeting educational needs of children in the community. In addition, the emphasis on service learning cultivates a sense of civic duty in nursing students. As well, GSBD exposes youth to nursing as a possible career choice: scouts see the simulation laboratory and classrooms in the College of Nursing while interacting with college students. Operationalizing this experience involves planning, implementation, and evaluation. Responsibilities are shared between the faculty member and troop leaders (see Table).

\section{Planning}

Selecting Girl Scout badges. Faculty select the badges that scouts will earn. Badges that include requirements related to content in the nursing course and lend themselves to learning activities for small groups are chosen, with consideration of time, resources, and nursing student abilities. A Healthier You, Caring for Children, and First Aid badges have been used successfully. Badges are rotated over 3 years to avoid repetition so that troops can return year after year. 


\section{Table}

Faculty Member's and Troop Leaders' Responsibilities

FACULTY MEMBER

FACULTY MEMBER

Write objectives and directions for assignment and add to syllabus

Select badge for scouts to earn

Choose dates and times in $2^{\text {nd }}$ half of semester

Make room reservations

Negotiate assignment of students to dates, groups, and badge requirements

Inform students of dress code

Provide informational flyers to scout leaders

Track reservations of troops

Make copies of evaluation forms for scouts and students

\section{Implementation}

Meet with student groups before GSBD to assure applicability of teaching plan

Communicate expected attendance to students about 2 days prior to event

Provide name tags, markers, pencils, and evaluation forms

Assist students with se- up

Remind students to observe growth and development of scouts

Assign students to meet and greet activities

Provide introductory welcome to scouts that promotes nursing as a career choice

Divide scouts into groups after opening remarks

Oversee presentations and intervene if problems arise

Involve students in distributing and collecting evaluation forms from scouts

Lead post- conference and ensure students complete service learning evaluation

\section{TROOP LEADERS}

\section{Planning}

Register troop for a GSBD

Arrange transportation

Obtain appropriate permissions

Complete badge requirements preparatory to attending GSBD
Transport scouts to and from GSBD

Monitor behavior of scouts

Assure scouts collect all belongings prior to departure

\section{Evaluation}

Review evaluations from scouts

Tally and analyze data collected from students' service learning evaluations

Grade student paper assignments

Determine opportunities for changes or

improvements for subsequent offerings
Assure that follow-up badge requirements are completed Purchase and award badges 
Scheduling. The faculty member chooses dates for GSBD that are in the second half of the semester because this allows time to notify troop leaders of the dates, for troops to register, and for students to prepare. Scheduling GSBDs after midterm also allows faculty to combine a review of the teaching objectives with the midterm clinical evaluation, thus eliminating the need to schedule additional appointments.

Preparing guidelines for the experience. Student objectives and written assignment guidelines should be clearly articulated in the course syllabus (see Figure 1). Two to three students are assigned a badge requirement because this GSBD experience lends itself to group work. At the beginning of the semester during clinical orientation, students form their own groups and negotiate the specific badge requirement that they will present. The variety of talents and personalities that merge in the groups offers students the opportunity to work in a situation that simulates the real world. This small group size encourages them to share responsibility for the tasks and provides them an opportunity to serve others.

Written assignment guidelines specify components to be included in the paper and the number of points assigned to each. These include teaching-learning objectives for the scouts, an outline of the content to be presented, a plan for developing age-appropriate teaching strategies, an evaluation of the implementation of the teaching, and recommendations for revisions. The written assignment culminates in a reflection on the meaning of the experience in relation to altruism, autonomy, human dignity, integrity, and social justice.

Faculty need to inform students of any dress code requirements on GSBDs. The GSBDs are regular clinical experiences and adherence to the dress code reinforces professional identity. For this experience, students wear polo shirts with the college logo and khaki pants. This consistent dress makes students easily identifiable to leaders and scouts.

Connecting with Girl Scout organizations. Troop leaders welcome opportunities to partner with others for scouts to earn badges. Although leaders are attuned to the developmental and social needs of scouts, they often lack the expertise or resources necessary for girls to meet badge requirements. Nursing students are able to augment troop leaders' skills, and through the GSBD experience, they can actualize the spirit of service leaning. 


\section{Figure 1 Directions for Girl Scout Badge Day Teaching Experience}

\section{Objectives:}

Upon completion of this experience, the learner will be able to:

1. Develop teaching learning objectives, an outline of the presentation/activity, and a teaching aid for use during the presentation/activity.

2. Implement appropriate methods of instruction based on the developmental level of the audience.

\section{Directions:}

1. Students will be assigned to work in groups. Student groups will develop their assigned topic.

One week prior to teaching experience groups will meet with the clinical instructor to discuss their plan for the upcoming teaching experience. A draft of the following must be brought to the meeting. (10 pts)
a. Teaching learning objectives
b. Outline of the presentation/activity
c. Teaching aid(s)

2. On the day of the teaching experience, dress in appropriate attire (no jeans, no tennis shoes, no revealing clothing, etc). Wear your lab coat (if appropriate - check with your clinical instructor) and name pin. Implement your teaching experience as outlined.

3. After the experience each group member will turn in the following assignment to the clinical instructor at the assigned time.
a. Title page (Included in APA pts)
b. Teaching learning objectives (10 pts)
c. Outline of presentation/activity (10 pts)
d. Teaching aid (s) (20 pts)
e. Reference list (Included in APA pts)
f. Evaluation of activity (25 pts)
g. Reflection of activity (15 pts)

The evaluation should be approximately 2 pages and include the following:

a. Was the content of the project appropriate for the developmental level of the audience? Were the learning objectives achieved? Discuss why objectives were met or not met. Include what revisions you would suggest if you were to do this project again. (15 pts)

b. What was the participants' response to the project? Did you hold their attention? Did they actively participate? What, if anything, would you do differently if you were to do this project again? (5 pts)

c. Comment on the environment, time of the project, and location. What changes would improve the project? (5 pts)

The reflection should be approximately 2 pages and include the following:

a. How was respect for others demonstrated during the experience? (5 pts)

b. Discuss whether or not nurses have an obligation to volunteer in the community to improve health. (5 pts)

c. How did this experience influence your understanding of social responsibility? (5 pts)

APA format followed (title page, reference list, and evaluation) and appropriate references used (10 pts). It is expected that 4 sections of the paper (title page, teaching learning objectives, outline, and teaching aid) will be the same for the group; however, the evaluation section and reference list should reflect the individual's work. This paper will be graded and will account for $5 \%$ of the course grade. 
Communication of GSBD opportunities is essential because, while troop leaders embrace such opportunities, they cannot participate if they are not informed. It is more efficient to use the established chain of communication in the Girl Scout system, rather than recruiting by word of mouth or notifying troop leaders who participated previously. Flyers, made by the faculty member, are an effective method to communicate dates and times to troop leaders.

Leaders are directed to contact the faculty member to make arrangements for a GSBD. Because leaders need a clear understanding of their responsibilities it is helpful to provide this information during the initial contact Reservations are handled on a first come first served basis since the number of scouts that can be accommodated is limited. GSBDs work best when enrollment is limited to 24-32 scouts. This allows groups of 6-8 scouts to rotate through the four selected badge requirements.

\section{Implementation}

At a meeting with faculty prior to GSBD, student groups present their teaching-learning objectives and an outline of the content and teaching aids. This required meeting discourages student procrastination and allows faculty to check the overall accuracy and appropriateness of content. Students then make necessary revisions. As an incentive to be prepared for the meeting, points towards their assignment grade are allocated for their planning. About 2 days before each GSBD, an e-mail is sent to students verifying the number of scouts attending so that sufficient supplies can be obtained.

Because one purpose of GSBDs is for students to implement the role of teacher, they are allowed latitude in how they structure their teaching. The faculty encourages students to develop creative and age-appropriate ways to meet badge requirements. For example, the badge requirement for identifying safe toys, a component in the Caring for Children badge, has been addressed in different ways. One group had scouts cut pictures of safe toys from a catalog and glue them onto a poster to make a collage. Another decided to teach about safe toys by bringing toys and a toy chest from home. Scouts were then asked to put safe toys into the toy chest and the nursing students asked what aspects made a particular toy safe or unsafe.

On GSBD, faculty responsibilities include welcoming participants and outlining a schedule for the event, ensuring the event proceeds smoothly, overseeing student presentations, having evaluation forms available, and leading post-conference. Students are assigned meet and greet tasks, with some posted at 
entry ways to direct scouts to the main classroom. Other students assist scouts as they prepare name tags. The faculty member greets leaders and confirms attendance numbers.

The program begins with all scouts and leaders assembled together in the main classroom. The faculty member welcomes scouts and gives an overview of what they will experience. Scouts are told that they will be divided into small groups and escorted to various classrooms by students. They are instructed that they can leave their belongings in the main classroom, because they will return there at the end of the day. This introductory time also provides an opportunity to promote nursing as a profession. Faculty encourage discussion by asking about the scouts' plans: "Does anyone know a nurse?", "Does anyone want to become a nurse?", and "Who wants to go to college?" Several students share why they are studying to become nurses.

Effort is made to keep troops together as much as possible, since each has a unique culture and scouts enjoy a sense of camaraderie that can be altered if troop members are separated. Scouts seem more comfortable sharing stories and engaging in discussions when they know the members of their group. Students escort groups of scouts to one of the various learning stations that correspond to badge requirements. Once scouts are assembled, students have 20 minutes to deliver content associated with the specific badge requirement. Every 20 minutes scouts move from one learning station to another until all requirements are completed.

After scouts complete all learning stations, they reassemble in the main classroom to complete evaluations. Students lend assistance by answering questions, helping to spell words, and collecting evaluations. As scouts gather their belongings, students thank them for participating. Scouts and leaders typically reciprocate by expressing their appreciation for the GSBD.

A post-conference, usually lasting about 30 minutes, is conducted immediately after the scouts depart. The focus of the discussion is growth and development. Students are challenged to provide examples of observed norms and behaviors and link these observations to theory. For example, students assess cognition by analyzing scouts' responses on evaluation forms. The faculty member encourages discussion about what activities were successful and what improvements could be made. Students are asked to make comparisons among the various groups and explain any differences they noticed. The reflective component of the experience is not addressed in post-conference because students need time to contemplate how GSBD fulfilled the principles associated with 
service learning. Purposefully excluding the self-reflective component in postconference is advantageous because it discourages bias that could result from group discussion.

\section{Evaluation Procedures}

Scouts formally evaluate GSBD using a faculty-developed form. Scouts are asked to indicate their grade level, what they liked best, how the experience could be improved, and to provide an overall rating of GSBD. This evaluative process not only provides ample feedback about GSBD to make recommendations about future offerings, but also offers examples for students to make observations about growth and development of scouts.

Students are expected to evaluate the service learning experience by completing a survey designed by the faculty member. Items measure how the experience affected student perceptions of the value of providing service to those in need.

The third component of evaluation is student grading. Students write papers that are graded according to how well they met the objectives of the assignment (see Figure 1). Papers can be submitted individually or by student group. The use of group papers reduces grading time and increases collaboration among students; however, group papers can inflate the grades of students who do not carry their share of the workload because papers count for $5 \%$ of the overall course grade.

\section{Student Outcomes}

Data from student evaluations indicate that this clinical experience has positively influenced their perceptions of being prepared to deliver communitybased nursing, the value of providing service, and how nursing is perceived in the community. However, results also indicate that this experience does not necessarily motivate students to work in settings where health care professionals are underrepresented. They do not believe that service should be mandatory for health care providers, but do believe that health care providers should participate in community service. Students recognize that nurses have expertise that can improve the health of individuals by voluntarily participating in service opportunities.

Data also confirm that the experience contributes to students' understanding of how to implement the role of teacher in the community. For 
example, because students have multiple encounters with scouts, they learn to make alterations in their methods. Students often find that too much content was planned for the time period and they quickly make changes for the next group.

\section{LESSONS LEARNED}

Once established, GSBD requires less organizational time than hospitalbased clinical experiences however, attention must be given to several matters. Including sufficient information during the first contact with the troop leader can save time. Specifying troop leader responsibilities, providing directions, and communicating a plan for canceling is important. Initially, phone calls were made the day before to remind troop leaders about GSBDs, but this practice has proved to be unnecessary because leaders were eager to participate.

Faculty should be prepared to intervene if problems arise during GSBDs. For example, students may have difficulty setting behavioral limits for scouts Intervening provides an opportunity for the faculty member to role model constructive ways to deal with behavior problems. Difficulties can also occur if students assigned to particular content withdraw from the course prior to GSBD. Since it is unfair to burden other students with the responsibility for missing content, having backup plans is wise. For example, showing a video about a health related topic can be a simple solution because little preparation is needed.

Making a modest amount of funds (US\$8.00 per group of students collaborating on a badge requirement) available to students to purchase supplies helps them to create more interactive learning experiences because expenses are not being borne by them. These funds can be used for teaching aids such as brochures, posters, craft supplies, or photo copying. Additionally, funds can be used to purchase small prizes and healthy snacks to serve as refreshments. If prizes or snacks are provided, it is important to assure that all scouts receive comparable items. While providing snacks is fun, it is important that snacks do not become a distraction to learning. As an example of this, one group gave scouts cookies and juice at the end of the session, and this disrupted the next session because they were still eating.

An environment conducive to learning is important for success. If possible, it is best to have one student group per room, since scouts can become distracted if more than one group is in the same room. Scouts prefer interactive sessions over lecture-style PowerPoint presentations, and therefore, noise can be a problem. As well, having too many scouts for the space can compromise learning. One semester only one GSBD was scheduled to reduce the amount of time faculty 
spent attending multiple GSBDs. This resulted in a very large group of approximately 100 scouts. While it was possible to accommodate all the nursing students and interested troops during this single date, having such a large group was unwieldy and is not recommended.

\section{POTENTIAL ENHANCEMENTS}

There are several ways GSBDs can be enhanced. It has been noted that some students easily make linkages between observations made during teaching sessions and growth and development theories, while others do not readily recall examples of scouts' behaviors. Reminding all students to pay attention to specific developmental norms may facilitate discussion in post-conference. Faculty can sensitize students to observe gross and fine motor coordination, interactions between scouts, nonverbal communication, language, and social skills. It is anticipated that this will help all students to integrate growth and development theory with concrete examples of behaviors.

Reflection is an important component of service learning. Typically, students write papers or journals to express their ideas. While these traditional methods are useful, faculty could initiate blogs or discussion boards as alternative mechanisms for students to share their reflections. Students may find blogging preferable to traditional methods. A limitation to this type of shared reflection could be that students, who read the blog before formulating their personal reflections, may become biased by reading the comments posted by other students. However, it is possible that students may find reading stimulates thoughts that they otherwise might not have developed.

With the increasing emphasis on evidence-based practice (Schmidt \& Brown, 2009), it would be advantageous to add a requirement for students to provide evidence for their selected content. Educational information should be based on best practices and therefore, students could be required to include a research article related to their topics as part of their pre-GSBD meeting with faculty.

\section{CONCLUSION}

GSBDs are an innovative alternative to traditional pediatric clinical experiences because badge requirements serve as a conduit for integrating the expertise of nursing students with the community need for health education. By preparing and conducting teaching sessions, students implement the role of 
teacher to meet course learning objectives. They are performing a service because they are addressing needs that may otherwise go unmet.

Many factors contribute to the success of GSBDs. The Girl Scout organization provides eager audiences in comparison to other community-based groups. In fact, the demand for badge opportunities has exceeded the number of student sessions that can be offered. Because badge requirements are predetermined, they serve as ready-made outlines for students to organize content. Students are energized through their interactions with scouts and are gratified to have their efforts appreciated. When this is the case, students are more likely to produce excellent teaching projects. Troop leaders appreciate the convenience of GSBD so they tend to return year after year. They recognize the value of this service learning experience for both scouts and students. The design of GSBDs embodies the philosophy of service learning while raising community awareness of nurses as sources of health information.

\section{REFERENCES}

American Association of Colleges of Nursing. (1998). The essentials of baccalaureate education for professional nursing practice. Washington, DC: Author.

American Association of Colleges of Nursing. (1999). Implementing communitybased education in the undergraduate nursing curriculum. Washington, D.C.: Author.

Astin, A. W., Vogelgesang, L. J., Ikeda, E. K., \& Yee, J. A. (2000). Executive summary. How Service Learning affects students. Los Angeles, CA: University of California, Higher Education Research Institute.

Bentley, R., \& Ellison, K. J. (2005). Impact of a service-learning project on nursing students. Nursing Education Perspectives, 26, 287-290.

Bittle, M., Duggleby, W., \& Ellison, P. (2002). Implementation of the essential elements of service learning in three nursing courses. Journal of Nursing Education, 41, 129-132.

Champagne, N. (2006). Service learning: Its origin, evolution, and connection to health education. American Journal of Health Education, 37, 97-102.

Greene, D. (1997). The use of service learning in client environments to enhance ethical reasoning in students. The American Journal of Occupational Therapy, 51, 844-852.

Eyler, J., \& Giles, D. E. (1999). Where's the learning in service-learning? San Francisco: Jossey-Bass. 
Hamner, J. B., Wilder, B., \& Byrd, L. (2007). Lessons learned: Integrating a service learning community-based partnership into the curriculum. Nursing Outlook, 55, 106-110.

Hester, J., Daniels, P., Adonis, T. A. (2005). Service-learning in nursing: Integrating student learning and community-based service experience through reflective practice. Health Sa Gesondheid, 10(4), 41-54.

Kendle, J., \& Zoeller, L. H. (2007). Providing time out: A unique service learning clinical experience. Annual Review of Nursing Education, 5, 53-75.

Kulewicz, S. J. (2001). Service learning: Head Start and a baccalaureate nursing curriculum working together. Pediatric Nursing, 27(1), 37-43.

Kushto-Reese, K., Maguire, M. C., Silbert-Flagg, J., Immelt, S., \& Shaefer, S. J. M. (2007). Developing community partnerships in nursing education for children's health. Nursing Outlook, 55, 85-94.

Learn and Serve America's National Service-Learning Clearinghouse. (2008). What is service learning? Retrieved February 28, 2008 from http://www.servicelearning.org/what is service-learning/servicelearning is/index.php

Lemon, B. S. (2001). A community needs assessment in a rural pediatric practice: Collaborative partners in health care. The Journal of Multicultural Nursing $\&$ Health, 7(3), 16-20.

Miller, M. P., \& Swanson, E. (2002). Service learning and community health nursing: A natural fit. Nursing Education Perspectives, 23, 30-33.

Reising, D. L., Allen, P. N., \& Hall, S. G. (2006a). Student and community outcomes in service-learning: Part 1 - Student perceptions. Journal of Nursing Education, 45, 512-515.

Reising, D. L., Allen, P. N., \& Hall, S. G. (2006b). Student and community outcomes in service-learning: Part 2 - Community outcomes. Journal of Nursing Education, 45, 516-518.

Schmidt, N. A., \& Brown, J. M. (2009). Evidence-based practice for nurses: Appraisal and application of research. Sudbury, MA: Jones and Bartlett.

Seifer, S. D. (1998). Service-learning: Community-campus partnerships for health professions education. Academic Medicine, 73, 273-277.

Silcox, H. C., \& Leek, T. E. (1997). International service learning: Its time has come. Phi Delta Kappan, 78, 615-618.

The Higher Learning Commission. (2003). Handbook of accreditation ( ${ }^{\text {rd }}$ ed.). Chicago: Author.

The International Partnership for Service-Learning and Leadership. (2006). IPSL declaration of principles. Retrieved February 28, 2008 from http://www.ipsl.org/advocacy/declaration-of-principles.html 